\title{
SPARK-LENGTH OF AN ELECTRIC INFLUENCE MACHINE, AS MODIFIED BY A SMALL SPARK FROM THE NEGATIVE SIDE.
}

\author{
By W. J. Humphreys,
}

\begin{abstract}
$A$ BOUT ten years ago I noticed that the discharging distance A between the poles of an ordinary Toepler machine could be very greatly increased by the aid of small sparks, taken by the hand or otherwise, from the negative pole, or from any part of the machine in metallic contact with it ; and also that this property was peculiar to the negative side, no such effect being produced by sparks taken from any of the positive parts.

Naturally I supposed that a description of this phenomenon, so easily and in fact often accidentally obtained from so common a machine, was to be found in the journals and larger treatises, but I have not been able to find any reference to it. I therefore venture to publish a short account of my experiments along this line, trusting that the results, if not new and interesting to all, may at least be so to many.

For the sake of convenience and clearness I refer to the accompanying sketch, in which $J, J$, are the two small leyden jars usually on electrical influence machines, $W$ the wire connecting their outer coatings, $A$ and $B$ the discharge balls. $C$ and $D$ connect, one with the positive the other with the negative comb of the machine.

Let the machine be run continuously, and let the distance between $A$ and $B$ be gradually increased till the sparks cease to pass. If a small spark is now drawn from any part of the machine metallically connected with the negative pole, the dilectric between $A$ and $B$ will in general break down and a spark of full magnitude pass between them.
\end{abstract}


In this way the sparking distance may be increased anywhere up to seventy-five per cent. or even more, the extent of increase depending on many things as will appear from the experiments described below.

The experiments were usually made with the machine in constant action, but this was only a matter of convenience as the discharges between the poles could still be forced, by the aid of a small spark from the negative side, after the machine had come to rest, but of course before the potential had dropped very greatly.

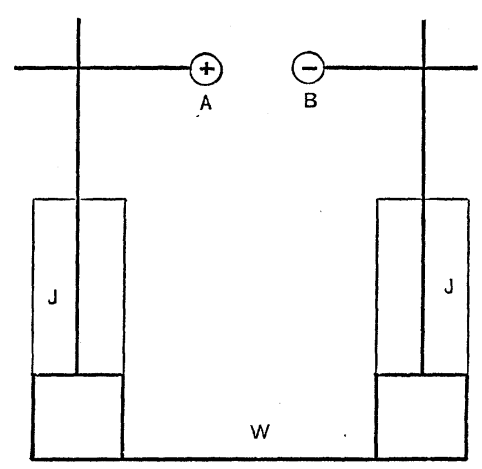

Fig. 1.

The phenomenon has been tried, and with uniform success, with several machines; among them an old type Holtz, Toepler and Wimshurst machines. Most of my observations however have been made with a two-plate Wimshurst machine, the plates being twenty inches in diameter, of ebonite and furnished with metallic sectors.

When the poles were equal in polish and otherwise it was, as one would expect, a matter of indifference which was positive and which negative, the forced spark being obtained equally well in each case.

The phenomenon has been tested under quite a number of conditions-some of which are the following. Where no statement to the contrary is made, the condensers belonging to the machine were used, and both poles kept polished. 
I. Roughened negative pole. Results never good; the negative pole lost its charge so rapidly in the form of a brush that it was impossible to obtain sparks of any considerable length.

2. Polished negative pole. Results generally very good.

3. Condensers of very small capacity. Increase in spark gap slight.

4. Condensers of large capacity. Spark gap not much increased.

5. No condensers. Spark gap not affected by spark from either pole.

6. Condensers belonging to machine, and polished negative pole. Results generally excellent.

7. State of the atmosphere such as to prevent high potential, machine giving only short sparks. Results less pronounced, the poorer the working of the machine.

8. Condition of the atmosphere such as to cause unusually long sparks. Increase of spark-length ordinarily not very great.

9. Working of machine such as to give sparks of medium length, from eight to twelve centimeters with the Wimshurst machine. Increase of spark-length most pronounced, often nearly doubling the distance between the poles.

Io. Poles separated very widely. In this case a spark could not be made to pass the whole distance, but each time a small spark was taken from the negative side a discharge passed from the positive pole and lost itself along many branches into the air. Nothing of this kind happened at the negative pole when a similar spark was drawn from the positive side.

I I. Discharge poles removed some distance, about seventy centimeters, from the revolving disks. Results the same as when the poles were in their usual positions.

I 2. Outsides of condensers connected by metal rod. Results excellent.

I3. Outsides of condensers connected by secondary of a large induction coil. Increase in sparking distance still very pronounced, but volume of spark diminished.

I4. Outside of condensers connected by a wet string. Increase in sparking distance still decided, but volume of spark greatly diminished. 
I 5. Condensers completely insulated from each other. Outsides temporarily grounded or not, but finally left insulated. In this case there was not the slightest indication of a spark on taking small discharges from either pole.

Various other arrangements were tried, but probably these are the most important, and from them it may be gathered that if the poles of an electrical influence machine be separated beyond their sparking distance, they will still allow a spark to pass, either as a unit from pole to pole, or as one losing itself in branches, each time a small spark is drawn from the negative side of the machine, provided that the outer coatings of the condensers are connected by a conductor; and further that nothing of the kind takes place when the condensers are insulated from each other, nor when the small spark is taken from the positive side of the machine.

It may be well to state that the size of the small spark necessary to cause the discharge between the poles is not the same under all conditions. When the poles are separated but little beyond their sparking distance it may be very slight, but has to be much larger when the distance between the poles is greatly increased.

The experiments of Lodge and others on the importance of electrical surges and oscillations in the production of sparks, would incline one to attribute the above phenomenon to some such cause. There is, however, one important objection to this explanation. If the phenomenon is really due to surges or oscillations, it is not clear why they should not be equally great, and the results just as pronounced when the side spark is taken from one pole as when it is taken from the other. Still, the fact that the phenomenon ceases when and only when the outer coatings of the jars are so insulated that there can be no oscillations or even surges between them, well nigh compells the acceptance of the above explanation, but in a distinctly modified form.

Let the jars be fully charged, and the poles separated too far to allow sparks to pass under ordinary conditions. The field of force due to these charges is a complicated one, depending of course to some extent on neighboring objects, but as a rough approximation it may be regarded as made up of lines of force between the poles $A$ and $B$ say of the figure, and a much greater number of lines 
of force from inner to outer coatings through the walls of the jars $J, J$. If the jars are insulated from each other a spark drawn from either $A$ or $B$ will decrease the strain between them. I assume the sparks to be taken with objects in connection with the earth, that is at zero potential. If, on the other hand, the outside coatings of the jars are so connected that oscillations or even one-way surges may pass between them a spark from either pole will cause an impulsive rush of the opposite charge to the other pole and a consequent rise of its potential. That the break-down takes place only when the auxiliary spark is taken from the negative side indicates that the dielectric is far more sensitive to shocks next the anode than it is next the cathode.

There are other indications, at least one of which I shall discuss in another paper, of the superior sensitiveness to electrical disturbances of the region about the positive over that about the negative pole. But this idea of sensitiveness of the dielectric next the anode, when under usual conditions, is already supported by certain experiments of Faraday, Macfarlane and De la Rue and Hugo Müller. In speaking of Faraday's experiments on discharges between spheres of different sizes, J. J. Thomson ${ }^{1}$ says : "We may express this result by saying that when the electric field is not uniform the gas does not break down so easily when the greatest electromotive intensity is at the cathode as it does when it is at the anode."

To explain this sensitiveness at the anode, we may assume that the molecules of the dielectric between the poles are polarized and formed into Grotthus' chains, and further that these chains are more easily broken down or ionized by shocks at one end than by shocks at the other or by steady strains. This hypothesis offers a common explanation of the above phenomenon and Jaumann's discovery $^{2}$ that a gas is electrically weaker under oscillating fields than under steady ones.

In the various experiments of Jaumann and other workers on the effects of oscillations in producing sparks there are no indications, so far as I know, whether it is the positive to negative pole or the reverse impulse that produces the spark, but if the above

\footnotetext{
1 Experimental Researches, p. 170.

${ }^{2}$ Sitzb. d. Wien Akad., 97, p. 765, r888.
} 
assumptions are true it would seem to be the former and not the latter.

Doubtless more or less close mechanical analogies to the assumption of a Grotthus' chain more sensitive to shocks at one end than at the other could be found, but at present I shall not search for them, since the assumption is offered more as a means of coördinating this with other experiments, and of suggesting possible lines of further work than as a complete and final explanation.

Rouss Physical Laboratory,

University of VA., March, Igoo. 